Proceedings of the International Symposium on Physics of Materials (ISPMA 14), September 10-15, 2017, Prague

\title{
Influence of Hydrogen-Charging Regime on Strain Hardening and Deformation Mechanism of Hot-Rolled High-Nitrogen Austenitic Steel
}

\author{
V.A. Moskvina ${ }^{a, b, *}$, E.G. Astafurova ${ }^{a}$, G.G. Maier $^{a}$, E.V. Melnikov ${ }^{a}$, \\ N.K. GalChEnKO ${ }^{a}$ AND S.V. Astafurov ${ }^{a}$ \\ ${ }^{a}$ Institute of Strength Physics and Materials Science, Russian Academy of Sciences, \\ Akademichesky av. 2/4, 634055 Tomsk, Russia \\ ${ }^{b}$ National Research Tomsk Polytechnic University, Lenin av. 30, 634050 Tomsk, Russia
}

\begin{abstract}
The effect of hot-rolling and electrochemical hydrogen-charging on strength properties, strain hardening and deformation mechanisms of a high-nitrogen austenitic vanadium-containing $\mathrm{Fe}-17 \mathrm{Cr}-24 \mathrm{Mn}-1.3 \mathrm{~V}-0.2 \mathrm{C}-0.8 \mathrm{~N}$ steel was studied by uniaxial tensile tests, scanning and transmission electron microscopy. Hydrogen-charging for 15 , 37, and $43 \mathrm{~h}$ reduces a yield strength, an ultimate tensile strength and elongation in the steel specimens. Hydrogencharging for 37-43 h leads to increase in strain-hardening coefficient at early degrees of deformation (up to $10 \%$ ) compared to uncharged and $15 \mathrm{~h}$-charged specimens. Hydrogen influences the deformation mechanisms of the high-nitrogen steel: besides dislocation slip, one of the main deformation mechanisms of hydrogen-containing steel specimens is mechanical twinning. Hydrogen-charging promotes twinning, microlocalization of a plastic flow and $\gamma \rightarrow \varepsilon$ martensitic transformation in the steel.
\end{abstract}

DOI: 10.12693/APhysPolA.134.760

PACS/topics: 81.40.Lm

\section{Introduction}

Recently, one of the actual problem of resource-saving technologies, particularly, in the area of hydrogen energy, is to prevent premature failure of the materials working in hydrogen-containing environments. Stable to $\gamma \rightarrow \alpha$ strain-induced transformation austenitic stainless steel is used as a base material for constructions working under hydrogen exposure, because of their high resistance to hydrogen embrittlement (HE) as compared with metastable austenitic or ferritic steels [1-4]. Bulk and surface charging of steels with hydrogen changes their crystal lattice parameters, electrochemical and mechanical properties. The most typical effect of hydrogen on the steel properties is the reduction of ductility and hydrogen embrittlement [1-5].

High-nitrogen steels (HNS) have unique combination of strength properties which depends on the steel chemical composition (concentration of nitrogen and the substitutional elements in solid solution), phase composition (austenite, ferrite, particles) and phase stability during plastic deformation (strain-induced $\gamma \rightarrow \varepsilon, \gamma \rightarrow \alpha^{\prime}$ martensitic transformations), grain size [5-7]. Due to the large number of possible phase and structural states in high-nitrogen steels, the question of hydrogen effect on their properties is still open. To date, relatively few papers have been published about the effect of hydrogen on deformation behavior of high-nitrogen containing steels $[1,2,8-12]$. Uhlemann and colleagues [8] estab-

*corresponding author; e-mail: valya_moskvina@mail.ru lished that the effect of $\mathrm{HE}$ is most characteristic for steels $18 \mathrm{Cr}-18 \mathrm{Mn}-0.57 \mathrm{~N}$ and $33 \mathrm{Cr}-30 \mathrm{Ni}-\mathrm{Mo}-0.38 \mathrm{~N}$ with a high content of interstitial atoms, while steels $27 \mathrm{Cr}-$ $31 \mathrm{Ni}-\mathrm{Mo}$ and $19 \mathrm{Cr}-25 \mathrm{Ni}-\mathrm{Mo}$ with lower content of nitrogen $(0.199 \mathrm{~N}$ and $0.192 \mathrm{~N} \mathrm{wt} \%$, respectively) are more resistant to hydrogen embrittlement. San Marchi et al. [9] found that nitrogen-containing austenitic steels $21 \mathrm{Cr}-$ $6 \mathrm{Ni}-9 \mathrm{Mn}-0.23 \mathrm{~N}$ and $22 \mathrm{Cr}-13 \mathrm{Ni}-5 \mathrm{Mn}-2 \mathrm{Mo}-0.35 \mathrm{~N}$ have a potential to replace the traditional 300 -series stainless steels which are used for the production of highpressure vessels for hydrogen storage. At the same time, Michler et al. [11] reported that $18 \mathrm{Cr}-18 \mathrm{Mn}-0.7 \mathrm{~N}$ and $18 \mathrm{Cr}-6 \mathrm{Mn}-8 \mathrm{Ni}-0.25 \mathrm{~N}$ nitrogen austenitic steels and $\mathrm{Cr}-$ Ni steels (not containing a high concentration of the interstitial atoms) have similar hydrogen-assisted fracture mechanism and alloying with $\mathrm{Mn}$ and $\mathrm{N}$ is not capable to replace expensive $\mathrm{Ni}$ in stable austenitic steels which are resistant to HE. Hereby, there is limited and contradictory information on the combined effect of hydrogen and nitrogen on properties of austenitic steels.

In this study, the effect of the duration of electrochemical hydrogen-charging on the tensile behavior (strain hardening, deformation mechanisms, strength properties and plasticity) of high-nitrogen austenitic vanadiumcontaining $\mathrm{Fe}-17 \mathrm{Cr}-24 \mathrm{Mn}-1.3 \mathrm{~V}-0.2 \mathrm{C}-0.8 \mathrm{~N}$ steel was investigated.

\section{Materials and experimental details}

Investigations were carried out for the steel with the chemical composition given in Table I. The initial billets with dimensions of $10 \times 10 \mathrm{~mm}^{2}$ were hot-rolled at $1150^{\circ} \mathrm{C}$ into sheets of $1 \mathrm{~mm}$ thickness and air cooled. A regular dog-bone shaped flat samples with the gage sections of 
TABLE I

Chemical composition (wt\%) of austenitic HNS

\begin{tabular}{c|c|c|c|c|c|c|c|c}
\hline \hline \multicolumn{1}{c}{ Elements [wt\%] } \\
\hline $\mathrm{Cr}$ & $\mathrm{Mn}$ & $\mathrm{Si}$ & $\mathrm{V}$ & $\mathrm{P}$ & $\mathrm{S}$ & $\mathrm{N}$ & $\mathrm{C}$ & $\mathrm{Fe}$ \\
\hline 17.25 & 23.79 & 0.94 & 1.33 & 0.04 & 0.01 & 0.81 & 0.21 & bal.
\end{tabular}

$1 \times 2.5 \times 18 \mathrm{~mm}^{3}$ were cut from the hot-rolled sheets using the electro-spark machine. Samples were mechanically ground and electrochemically polished in a solution of $50 \mathrm{~g}$ of $\mathrm{CrO}_{3}$ in $200 \mathrm{ml}$ of $\mathrm{H}_{3} \mathrm{PO}_{4}$ at room temperature. Electrochemical hydrogen charging of tensile samples was conducted at a current density of $10 \mathrm{~mA} / \mathrm{cm}^{2}$ for 15,37 , and $43 \mathrm{~h}$ at room temperature in $3 \% \mathrm{NaCl}$ water solution containing $3 \mathrm{~g} / \mathrm{l}$ of $\mathrm{NH}_{4} \mathrm{SCN}$ as recombination poison. Hydrogen-charged samples were stored in liquid nitrogen before tensile tests. The tensile tests of the steel specimens were performed at room temperature and an initial strain rate of $4.6 \times 10^{-4} \mathrm{~s}^{-1}$ using LFM-125 (Walter+Bai AG) electromechanical machine. To quantitatively describe the HE of the specimens, the hydrogen embrittlement index $k_{H}$ was calculated:

$$
k_{H}=\left[\left(\delta_{\text {Uncharged }}-\delta_{H-\text { charged }}\right) / \delta_{\text {Uncharged }}\right] \times 100 \%,
$$

where $\delta_{U \text { uncharged }}$ and $\delta_{H \text {-charged }}$ are the elongations of hydrogen-free and hydrogen-charged specimens.

For microstructural characterization, electron microscopy studies were performed using a JEOL 2100 transmission electron microscope (TEM) with an accelerating voltage of $200 \mathrm{kV}$. TEM-samples in the form of $3 \mathrm{~mm}$ diameter discs were electropolished in a solution of $95 \%$ glacial acetic acid $\left(\mathrm{CH}_{3} \mathrm{COOH}\right)+5 \%$ perchloric acid $\left(\mathrm{H}_{3} \mathrm{ClO}_{4}\right)$. The scalar dislocation density was determined using the method described in [13]. X-ray diffraction (XRD) analysis was carried out using DRON7 X-ray diffractometer with $\mathrm{Co}_{\alpha} K_{\alpha}$ radiation. Altami MET 1C light microscope was used to characterize the grain size of the specimens. Fracture and side surfaces of the specimens were examined by a LEO EVO 50 (Zeiss) scanning electron microscope (SEM). Magnetic properties of steel (magnetophase analysis) were evaluated at room temperature using magnetometer $\mathrm{H}-04$.

\section{Results and discussion}

According to XRD analysis, after hot rolling the samples of HNS have an austenitic structure with a lattice parameter $a=0.363 \mathrm{~nm}$, which evidences the presence of high concentration of interstitial atoms $(\mathrm{C}$ and $\mathrm{N})$ in solid solution. The average grain size determined by light microscopy is $14.0 \pm 0.5 \mu \mathrm{m}$. TEM studies show that the initial steel structure contains a high dislocation density of $\rho=3 \times 10^{14} \mathrm{~m}^{-2}$ and coarse particles $(\mathrm{V}, \mathrm{Cr})(\mathrm{N}, \mathrm{C})$ with diameter of $0.2-0.4 \mu \mathrm{m}$. As XRD patterns indicate the presence of the austenitic phase only, the volume fraction of these particles $(\mathrm{V}, \mathrm{Cr})(\mathrm{N}, \mathrm{C})$ does not exceed $5 \%$. Both XRD and magnetophase analyses have not identified ferritic phase in the initial structure of steel.
Figure 1a shows the tensile true stress-true strain curves for the hydrogen-free and hydrogen-charged samples. Mechanical properties of HNS after hot rolling are characterized by a yield strength $\sigma_{Y S}=1270 \mathrm{MPa}$ and an ultimate tensile strength $\sigma_{U T S}=1580 \mathrm{MPa}$ with elongation $\mathrm{EL}=17 \%$. The yield strength, ultimate tensile strength, and EL have a tendency to decrease with increasing of the hydrogen-charging duration, but stages of plastic flow and the strength properties of HNS do not change significantly.

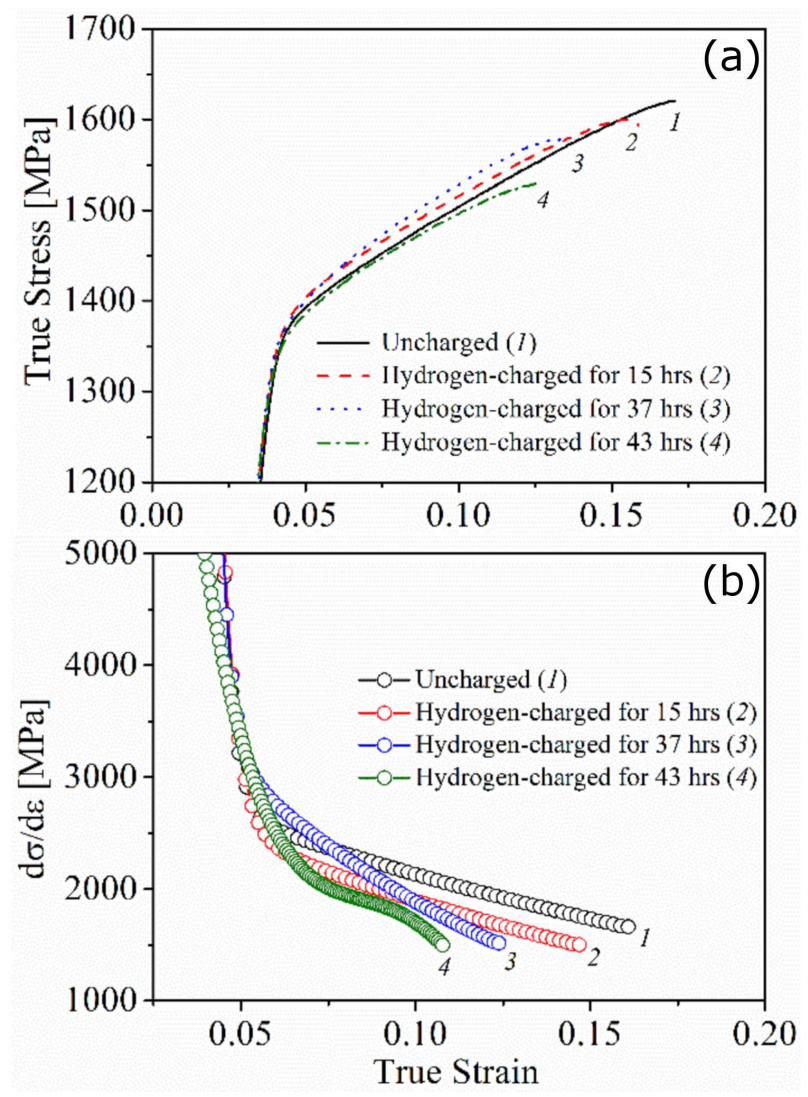

Fig. 1. Tensile true stress-true strain curves (a) and work-hardening rate $(\mathrm{d} \sigma / \mathrm{d} \varepsilon)$ versus true strain (b) for uncharged and hydrogen-charged samples.

The decrease in strength properties $\left(\sigma_{Y S}\right.$ and $\left.\sigma_{U T S}\right)$ in hydrogen-charged samples shows that hydrogen does not promote solid solution strengthening of austenite as was observed for low-interstitial-alloyed 310-series steels [14] as well as for carbon- and nitrogen-containing metastable steels [1]. In contrast, hydrogen saturation reduces the yield strength of steel (Fig. 1a) due to ability of hydrogen to facilitate migration of dislocations and to promote to the development of a planar slip as it was shown for austenitic stainless steels in $[15,16]$.

Hydrogen-charging for $15-43 \mathrm{~h}$ leads to relatively high loss of ductility and $k_{H}$ is 24 and $35 \%$, respectively. In spite of the fact that EL of steel decreases after 37 and $43 \mathrm{~h}$ of hydrogen-charging, its values remain quite high (11\%). 
Figure $1 \mathrm{~b}$ shows the work-hardening rate $(\mathrm{d} \sigma / \mathrm{d} \varepsilon)$ versus true strain for hydrogen-free and hydrogen-charged samples. Strain-hardening rate decreases during plastic deformation of hydrogen-free sample and neck forms at $\mathrm{d} \sigma / \mathrm{d} \varepsilon \sim \sigma$ (Fig. 1b) in accordance with wellknown Considere criterion on plastic flow instability [17]. After hydrogen-charging for $15 \mathrm{~h}$, a d $\sigma / \mathrm{d} \varepsilon(\varepsilon)$-dependence flows similarly to samples deformed without hydrogencharging. The negligible decrease in work-hardening rate was observed after hydrogen-charging for $15 \mathrm{~h}$ is probably due to hydrogen-assisted facilitation of dislocation moving and increase in slip planarity, as shown by authors of $[12,16]$. Hydrogen-charging up to 37 and $43 \mathrm{~h}$ contributes to a rise in work-hardening rate at early stages of plastic deformation, but strainhardening coefficient $\mathrm{d} \sigma / \mathrm{d} \varepsilon$ decreases faster with strain as compared to $15 \mathrm{~h}$ hydrogen-charged and uncharged samples (Fig. 1b).
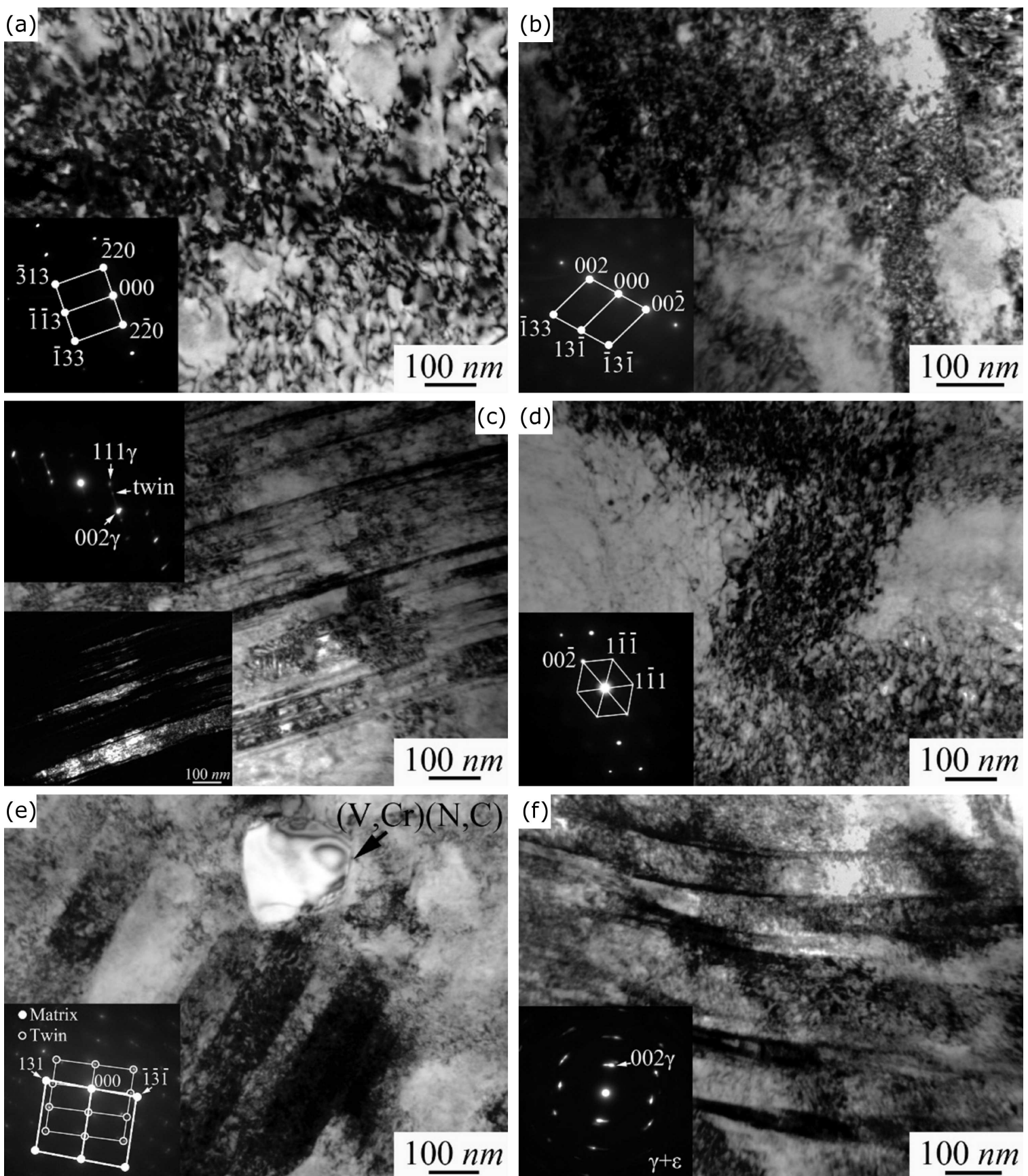

Fig. 2. Bright-field TEM images of dislocation arrangement and SAED patterns (insets in (a-f)) for uncharged (a-c) and hydrogen-charged specimens $(\mathrm{d}-\mathrm{f})$ : (a) initial structure after hot rolling, (b,c) after tensile deformation of hydrogenfree specimen, (d-f) after tensile deformation hydrogen-charged for $37 \mathrm{~h}(\mathrm{~d}, \mathrm{e})$ and for $43 \mathrm{~h}(\mathrm{f})$ specimens. Dark-field image to (c) was obtained in twin reflection. Selected area diffraction patterns were obtained from the areas of $0.90 \mu \mathrm{m}^{2}$. 
TEM analysis indicates a high density of homogeneously distributed dislocations $\left(\rho=3 \times 10^{14} \mathrm{~m}^{-2}\right)$ in steel after hot rolling (Fig. 2a). Tensile deformation of hydrogen-free samples is associated with accumulation of slip dislocations and mechanical twinning (Fig. 2b). The dislocations are homogeneously distributed with a tendency to form cells and dislocation walls with a high density of dislocations in specimens of HNS deformed without hydrogen-charging. The value of dislocation density could be hardly evaluated using TEM images, but according to TEM contrast it increases to $\rho \approx 10^{15} \mathrm{~m}^{-2}$ (Fig. 2b). In addition to the high density of dislocations, mechanical twins of $30-80 \mathrm{~nm}$ in width were observed in the steel structure after tensile deformation (Fig. 2c).

HNS promotes the development of mechanical twinning due to the ability of nitrogen to decrease the stacking fault energy of steels and, at the same time, to increase their strength properties. Hereby, the critical shear stresses for twinning in such steels are attained at room temperature and at low strain [7, 18]. After tension, specimens hydrogen-charged for 37 and $43 \mathrm{~h}$ have dislocation arrangements similar to hydrogen-free one (Fig. 2d). After electrolytic hydrogen-charging for 37 and $43 \mathrm{~h}$, deformation twinning remains one of the main deformation mechanisms in HNS, which predominates in the steel structure and is accompanied with microlocalization of plastic deformation and with $\gamma \rightarrow \varepsilon$ martensitic transformation in tension (Fig. 2e,f). On the one hand, this behavior is associated with a decrease of the stacking fault energy of austenite, when alloying of steel with hydrogen [17], and, on the other hand, with "screening" of dislocations by hydrogen atoms and increase of their mobility [19].

SEM observations show ductile transcrystalline fracture mode both in fractured hydrogen-free and hydrogencharged specimens. SEM studies of fracture surfaces of the HNS indicate that a brittle layer $(\approx 3-5 \mu \mathrm{m})$ is formed on the side-surfaces of samples, the thickness of this brittle layer increases with the duration of hydrogencharging. The thin surface layer is destroyed in brittle, cleavage-like manner and the central parts of the samples are characterized by a ductile transcrystalline fracture mode. After hydrogen-charging and tension, on the side surfaces of the specimens numerous cracks located near the fracture zone and directed perpendicular to the tensile axis were observed, which appear as a result of cracking of the thin surface hydrogenated layer. Thereby, SEM observations show a predominantly ductile dimple fracture of the initial (hydrogen-free) and hydrogen-charged samples of HNS (except for thin surface layer). Similar results were obtained for $\mathrm{Fe}-17.7 \mathrm{Cr}-$ $14.7 \mathrm{Mn}-0.35 \mathrm{~N}-0.17 \mathrm{C} \quad[12], 21 \mathrm{Cr}-6 \mathrm{Ni}-9 \mathrm{Mn}-0.23 \mathrm{~N}$ and $22 \mathrm{Cr}-13 \mathrm{Ni}-5 \mathrm{Mn}-2 \mathrm{Mo}-0.35 \mathrm{~N}$ [9], Fe-17Cr-24Mn-1.3V$0.2 \mathrm{C}-1.3 \mathrm{~N}$ steels [20], which also demonstrated the ductile dimple fracture mode after hydrogen-charging.

The decrease in the ductility of steel after hydrogencharging can be caused by various factors - hydrogenenhanced strain-induced phase transformations [2], mi- crostructural changes (twinning, increase in dislocation density, microlocalization of plastic flow and slip localization, etc.) $[16,21]$, the availability of particles [11] and grain boundaries [22-24]. The authors [10] reported that chromium nitrides in HNS are able to absorb and accumulate a small amount of hydrogen in comparison with bulk saturation of grains. Analysis of TEM images supports the fact that the particles $(\mathrm{V}, \mathrm{Cr})(\mathrm{N}, \mathrm{C})$ do not deform when samples are strained with or without hydrogen. Magnetophase analysis of the samples after hydrogen-charging and deformation by uniaxial tension indicates that $\gamma \rightarrow \alpha^{\prime}$ strain-induced transformation is not realized in the steel. Notably, phase transformations and particles are less probable factors affecting the observed hydrogen embrittlement of $\mathrm{Fe}-17 \mathrm{Cr}-24 \mathrm{Mn}-1.3 \mathrm{~V}-$ $0.2 \mathrm{C}-0.8 \mathrm{~N}$ steel.

In consideration of the fact that steel after hot rolling had a high density of dislocations, hydrogen, apparently, had a tendency to accumulate near the dislocation cores, not only at grain boundaries. Numerous surface cracks are the result of cleavage in thin hydrogen-associated brittle layer (the diffusion zone of hydrogen saturation after electrochemical charging). Surface cracks are stress concentrators and have an effect on the fracture behaviour of subsurface hydrogen-saturated zone in the sample (a zone saturated with hydrogen under tension due to the migration of hydrogen atoms on defects of a crystal structure and stress-assisted diffusion), but the main part of the hydrogen-charged specimens fractures in ductile transgranular mode. Igata et al. [12] suggested that a possible reason for the change of character of fracture for $\mathrm{Fe}-17.7 \mathrm{Cr}-14.7 \mathrm{Mn}-0.35 \mathrm{~N}$ steel is an increase of planarity of slip due to hydrogen-assisted decrease of stacking fault energy and the suppression of cross-slip or initiation of HELP-effect [21]. In our case, surface embrittlement can also be explained with the activation of mechanical twinning when alloying with hydrogen.

\section{Conclusion}

Electrochemical hydrogen charging reduces the yield strength, ultimate tensile strength and elongation of high-nitrogen austenitic $\mathrm{Fe}-17 \mathrm{Cr}-24 \mathrm{Mn}-1.3 \mathrm{~V}-0.2 \mathrm{C}-$ $0.8 \mathrm{~N}$ steel. Nevertheless, after $43 \mathrm{~h}$ of hydrogen-charging steel still possesses high ductility and tensile properties.

Stages of stress-strain curves of $\mathrm{Fe}-17 \mathrm{Cr}-24 \mathrm{Mn}-$ $1.3 \mathrm{~V}-0.2 \mathrm{C}-0.8 \mathrm{~N}$ steel changes weakly under hydrogencharging. At the same time, the strain hardening coefficient decreases insignificantly for $15 \mathrm{~h}$-hydrogenated specimens, while hydrogen-charging for $37-43 \mathrm{~h}$ leads to increase of strain hardening rate at early degrees of deformation and rapid drop with increase of strain.

Hydrogen promotes the formation of a brittle layer (up to $5 \mu \mathrm{m}$ in a thickness) on side-surfaces of HNS specimens, which is ruptured by the cleavage mechanism and results in intensive cracking of the side surfaces of the specimens during tensile tests.

Hydrogen affects the deformation mechanisms of the steel. In the initial states after tension in the microstruc- 
ture of steel the main mechanism of plastic deformation is dislocation slip and twinning. Hydrogen-charging of HNS contributes to mechanical twinning and is accompanied with microlocalization of slip and activation of $\gamma \rightarrow \varepsilon$ martensitic transformation.

\section{Acknowledgments}

This research was supported by the Russian Science Foundation (project 17-19-01197). The studies were conducted using the equipment of Institute of Strength Physics and Materials Science (NANOTECH center).

\section{References}

[1] M.P. Phaniraj, H.J. Kim, J.Y. Suh, J.H. Shim, S.J. Park, T.H. Lee, Int. J. Hydrog. En. 40, 13635 (2015).

[2] P. Rozenak, J. Mater. Sci. 25, 2532 (1990).

[3] L. Zhang, Z.Y. Li, J.Y. Zheng, Y. Zhao, P. Xu, C. Zhou, X. Li, Int. J. Hydrog. En. 38, 8208 (2013).

[4] D. Eliezer, D.G. Chakrapani, C.J. Altstetter, E.N. Pugh, Metall. Trans. A 10, 935 (1979).

[5] V.G. Gavriljuk, H. Berns, High Interstitial Stainless Austenitic Steels, Springer, Berlin 2013.

[6] O.A. Bannykh, V.M. Blinov, M.V. Kostina, Met. Sci. Heat Treatm. 12, 43 (2003).

[7] V.G. Gavrilyuk, H. Berns, High Nitrogen Steel, Springer, Berlin 1999.

[8] M. Uhlemann, U.K. Chatterjee, S. Ningshen, H.J. Klauss, F. Schneider, J. Sci. Technol. 18, 1179 (2002).
[9] C. San Marchi, D.K. Balch, K. Nibur, B.P. Somerday, J. Press. Vessel Technol. Trans. AIME 130, 1 (2008).

[10] M.F. Shehata, S. Schwarz, H.J. Engelmann, M. Uhlemann, Mater. Sci. Technol. 13, 1016 (1997).

[11] T. Michler, J. Naumann, Int. J. Hydrogen Energy 35 1485 (2010)

[12] N. Igata, T. Fujiga, H. Yumoto, J. Nucl. Mater. 179181, 656 (1991)

[13] D.B. Williams, C.B. Carter, Transmission Electron Microscopy, Springer, USA 2009.

[14] D.P. Abracham, C.J. Altstetter, Metall. Mater. Trans. A 26A, 2849 (1995).

[15] D.P. Abracham, C.J. Altstetter, Metall. Mater. Trans. A 26A, 2859 (1995).

[16] V.G. Gavrilyuk, V.N. Shivanyuk, B.D. Shanina, Acta Mater. 53, 5017 (2005).

[17] W. Backofen, Deformation Processing, Metallurgia, Moscow 1977.

[18] Yu.I. Chumlyakov, I.V. Kireeva, A.D. Korotaev, E.I. Litvinova, Yu.L. Zuev, Rus. Phys. J. 39, 189 (1996).

[19] I.M. Robertson, Eng. Fracture Mech. 68, 671 (2001).

[20] E.G. Astafurova, V.A. Moskvina, G.G. Maier, E.V. Melnikov, G.N. Zakharov, S.V. Astafurov, N.K. Galchenko, J. Mater. Sci. 52, 4224 (2017).

[21] H.K. Birnbaum, P. Sofronis, Mater. Sci. Eng. A176, 191 (1994).

[22] I.J. Park, S. Lee, H. Jeon, Y.K. Lee, Corros. Sci. 93 , 63 (2015)

[23] N. Zan, H. Ding, X.F. Guo, Z.Y. Tang, W. Bleck, Int. J. Hydrog. En. 40, 10687 (2015).

[24] Y. Mine, K. Tachibana, Z. Horita, Metall. Mater. Trans. A 41A, 3110 (2010). 